\title{
Tetanically Induced LTP Involves a Similar Increase in the AMPA and NMDA Receptor Components of the Excitatory Postsynaptic Current: Investigations of the Involvement of mGlu Receptors
}

\author{
John J. O'Connor, ${ }^{1, a}$ Michael J. Rowan, ${ }^{1}$ and Roger Anwyl ${ }^{2}$ \\ ${ }^{1}$ Departments of Pharmacology and Therapeutics, and ${ }^{2}$ Physiology, Trinity College, Dublin, 2, Ireland
}

\begin{abstract}
Whole-cell patch-clamp recordings of evoked excitatory postsynaptic currents (EPSCs) were made from granule cells of the rat dentate gyrus in vitro. Tetanic stimulation in control media evoked a statistically identical long-term potentiation (LTP) of both the AMPA and NMDA receptormediated components of the dual component EPSC (AMPAR and NMDAR EPSCs), as shown by a similar percentage increase in both components when measured at a holding potential of $-30 \mathrm{mV}$, and also by an identical time course of the pre- and post-LTP induced EPSC at $-30 \mathrm{mV}$ and $-70 \mathrm{mV}$. Application of the selective metabotropic glutamate receptor (mGluR) agonist 1S,3R-ACPD induced a transient depression followed by a rapid onset LTP of both the AMPAR and the NMDAR components of the dual component EPSC. The ACPD- and tetanically induced LTP of the AMPAR EPSC was NMDAR dependent, being abolished by the NMDAR antagonist AP5. Tetanic stimulation, and application of ACPD, also induced a relatively rapid onset LTP of the pharmacologically isolated NMDAR EPSC. Such tetanically and ACPD-induced LTP of the isolated NMDAR EPSC was also dependent on NMDAR activation, being strongly inhibited by AP5. The tetanically and the ACPDinduced LTP of the NMDAR EPSC were dependent on protein kinase $C$ (PKC) stimulation, being strongly inhibited by the PKC inhibitor PKCl (19-31). The studies suggest that coactivation of the mGluR and NMDAR are required for induction of LTP of both the AMPAR- and NMDAR-mediated synaptic transmission. Moreover, LTP of the NMDAR-mediated synaptic transmission appears to be dependent on coincident activation of the NMDAR and mGluR.
\end{abstract}

[Key words: 1S,3R-ACPD (1-amino-cyclopentane-1,3-dicarboxylic acid), long-term potentiation, excitatory postsynaptic currents, AMPA receptors, NMDA receptors, metabotropic glutamate receptors]

Glutamatergic synaptic transmission in the hippocampus involves the activation of two types of postsynaptic glutamate receptors, $\alpha$-amino-3-hydroxy-5-methyl-4-isoxazoleproprionate (AMPAR) and $N$-methyl-D-aspartate (NMDAR). It has been

\footnotetext{
Received Apr. 29, 1994; revised Aug. 31, 1994; accepted Sept. 6, 1994.

This research was supported by the Health Research Board, Ireland, and the Welleome Trust.

Correspondence should be addressed to Dr. Roger Anwyl at the above address.

aPresent address: Department of Human Anatomy and Physiology, University College, Earlsford Terrace, Dublin, 2, Ireland.

Copyright $(\mathcal{C} 1995$ Society for Neuroscience 0270-6474/95/152013-08 $\$ 05.00 / 0$
}

well established that tetanic stimulation induces an NMDARdependent long-term potentiation (LTP) of AMPA receptor-mediated excitatory postsynaptic potentials and currents (referred to as AMPAR EPSPS/EPSCs) in the hippocampus (reviewed by Bliss and Collingridge, 1993). Tetanically induced LTP of the NMDAR-mediated responses has been more controversial. LTP of the pharmacologically isolated NMDAR-mediated responses was first demonstrated by Bashir et al. (1991), who found that LTP of the pharmacologically isolated NMDAR-mediated field EPSP and EPSC (referred to as NMDAR EPSPs/EPSCs) in the rat hippocampal slice was evoked following tetanic stimulation in CA1 of the hippocampal slice. Such LTP of isolated NMDAR EPSPs/EPSCs was later confirmed (Berretta et al., 1991; Asztely et al., 1992; Xie et al., 1992). However, several studies have reported that LTP of the NMDAR component of the normal dual component AMPAR/NMDAR EPSP/EPSC either did not occur or was much smaller than the LTP of the AMPAR component (Kauer et al., 1988; Muller and Lynch, 1988; Muller et al., 1992, 1988; Perkel and Nicoll, 1993).

Both AMPAR- and NMDAR-mediated responses have previously been found to be potentiated in the hippocampus following activation of metabotropic glutamate receptors (mGluR). Thus application of the sclective mGluR agonist 1-aminocyclopentane-1,3-dicarboxylic acid (ACPD) (Palmer et al., 1989) led to a very slowly developing potentiation (peak reached in 90 min) of the AMPA receptor-mediated field EPSPs in the rat CA1, such potentiation being NMDAR independent (Bortolotto and Collingridge, 1993). Moreover, ACPD application evoked potentiation of NMDAR-mediated responses, which were either of an acute reversible short-term type, as shown in hippocampal CA1 (Harvey et al., 1991; Aniksztejn et al., 1992; Behnisch and Reymann, 1993; Harvey and Collingridge, 1993), rat spinal dorsal horn neurons (Bleakman et al., 1992), and Xenopus oocytes (Kelso et al., 1992), or of a long-term type, as shown recently in dentate gyrus (O'Connor et al., 1994), olfactory cortex (Collins, 1993), and spinal dorsal horn neurons (Cerne and Randic, 1992).

We have recently provided substantial evidence that endogenous transmitter activation of mGlu receptors underlies LTP of the pharmacologically isolated NMDAR EPSC (O'Connor et al., 1994). In the present article we have extended this study, showing that a similar amplitude LTP of the NMDAR- and AMPARmediated component of the dual component AMPAR/NMDAR EPSC occurs following tetanic stimulation. We also present evidence that mGluR activation may underlie LTP of the AMPARmediated component of the dual EPSC. In addition, we have studied the NMDAR dependency of LTP of the AMPAR and 
NMDAR EPSC, and the effects of a protein kinase C (PKC) inhibitor on the LTP of the NMDAR EPSC.

\section{Materials and Methods}

Slice preparation. All experiments were carried out on transverse slices of the hippocampus of the rat (weight 100-150 gm). The brains were rapidly removed after decapitation and placed in cold oxygenated $(95 \%$ $\mathrm{O}_{2} / 5 \% \mathrm{CO}_{2}$ ) media. Slices were cut at a thickness of $350 \mu \mathrm{m}$ using a Camden vibroslice, and transferred to a storage container containing oxygenated media at room temperature. The slices were then transferred as required to a recording chamber for submerged slices, and continuously superfused at a rate of $5 \mathrm{ml} / \mathrm{min}$ with oxygenated media at 30 $32^{\circ} \mathrm{C}$.

Solutions and drugs. The control media contained (mM) $\mathrm{NaCl}, 120$; $\mathrm{KCl}, 2.5 ; \mathrm{NaH}_{2} \mathrm{PO}_{4}, 1.25 ; \mathrm{NaHCO}_{3}, 26 ; \mathrm{MgSO}_{4}, 2.0 ; \mathrm{CaCl}_{2}, 1.5$; and D-glucose, 10. All solutions contained $100 \mu \mathrm{M}$ picrotoxin (Sigma) to block $\mathrm{GABA}_{\mathrm{A}}$-mediated currents. Additional drugs used were 6-cyano7-nitroquinoxaline-2,3-dione (CNQX, Tocris Neuramin Ltd), D-2-amino-5-phosphonopentanoate (AP5, Tocris Neuramin Ltd), aminocyclopentane-1S,3R-dicarboxylic acid (1S,3R-ACPD), and the PKC inhibitor PKC(19-31) (PKCI, Bachem). These drugs were applied to the preparation in the perfusing media. The patch-clamp electrode contained (mM) potassium gluconate, $130 ; \mathrm{KCl}, 10 ; \mathrm{FGTA}, 10 ; \mathrm{CaCl}_{2}, 1 ; \mathrm{MgCl}_{2}$ 3; HEPES, 20; $\mathrm{Na}_{2}$ ATP, NaGTP, 0.5; QX 314, 5; pH 7.2 (using KOH). Such an intracellular medium should give free internal concentrations of $\mathrm{Ca}$ and $\mathrm{Mg}$ of approximately $17.5 \mathrm{nM}$ and $275 \mu \mathrm{M}$, respectively Some experiments were carried out using cesium methanesulfonate (130 $\mathrm{mM}$ ) in place of potassium gluconate with no resulting difference in the properties of the NMDA receptor.

Stimulation and recording. Whole-cell patch-clamp recordings (seal resistance $>4 G \Omega$ ) were made from dentate granule cells with patch pipettes (resistance 5-8 MS), using a List EPC-7 amplifier ( $3 \mathrm{kHz}$ lowpass Bessel filter). Previously described procedures (Hestrin et al., 1990; Keller et al., 1991) were used to verify the adequacy of the clamping, and experimental data were collected only from cells showing high quality clamping of the activated synapses. The capacitive current was always electronically canceled and the series resistance $\left(R_{S}\right), 8-20 \mathrm{M} \Omega$ as measured directly from the amplifier, compensated by $60-70 \%$. $R_{s}$ was also measured directly in several cells from the peak amplitude of the capacitive current, $I_{C}$ (without low-pass filtering), as $R_{S}-E_{l} / I_{C}$, where $E$ is the amplitude of the test pulse, usually $10 \mathrm{mV}$, giving values of 14-20 M $\Omega$ The mean input resistance was $258 \pm 26 \mathrm{M} \Omega$ and the mean resting potential $-69 \pm 4 \mathrm{mV}$. The inpul resistance was monitored continuously, and the recording terminated if it varied by more than $10 \%$.

Presynaptic stimulation was applied to the commissural/association pathway at a distance of $50 \mu \mathrm{m}$ from the cell body layer of the granule cells. Stimuli of $100 \mathrm{msec}$ duration and 4-15 V intensity were applied with bipolar electrodes made from thin Teflon-coated wires $(10 \mu \mathrm{m})$. The cell membrane potential was held at $-70 \mathrm{mV}$ throughout the recording period except for brief periods when steps were made to -30 $\mathrm{mV}$ for a duration of $300 \mathrm{msec}$. Full experiments were carried out providing that certain criteria were met. These included a resting potential of at least $-65 \mathrm{mV}$, a high input resistance $(>200 \mathrm{M} \Omega$ ), and a low threshold and steep input-output curve of the EPSCs. EPSCs were recorded at a control frequency of $0.05 \mathrm{~Hz}$, with the stimulation intensity adjusted to evoke an EPSC which was $20-30 \%$ of the maximum amplitude, usually $30-80 \mathrm{pA}$ for NMDA EPSCs and $120-180 \mathrm{pA}$ for AMPA EPSCs. The EPSCs were routinely stable for greater than 45 min. NMDA EPSCs recorded under whole-cell conditions were pharmacologically isolated with $4-10 \mu \mathrm{M}$ CNQX and $100 \mu \mathrm{M}$ picrotoxin in the perfusing solution, and QX $314(5 \mathrm{~mm})$ in the patch electrode, to block the AMPA, GABA , and $\mathrm{GABA}_{\mathrm{B}}$ receptor-mediated components of synaptic transmission, respectively. LTP was induced by tetanic stimulation consisting of eight trains each of eight pulses at $200 \mathrm{~Hz}$, intertrain interval $2 \mathrm{sec}$, under current-clamp conditions for the duration of the tetanus. The frequency of occurrence of LTP in the present studies was very high, over $85 \%$, providing that there was a strict adherence to the criteria described above. Following formation of the whole-cell seal, EPSCs were always recorded for $10 \mathrm{~min}$ to allow for stabilization before tetanic stimulation or agents were given.

Data analysis. Recordings were analyzed using the STRATHCLYDE electrophysiology software (Dr. J. Dempster). The measurements of 10 $90 \%$ rise times, peak amplitudes, and decay times were performed on the averages of three consecutive EPSCs. Curve fitting of single and
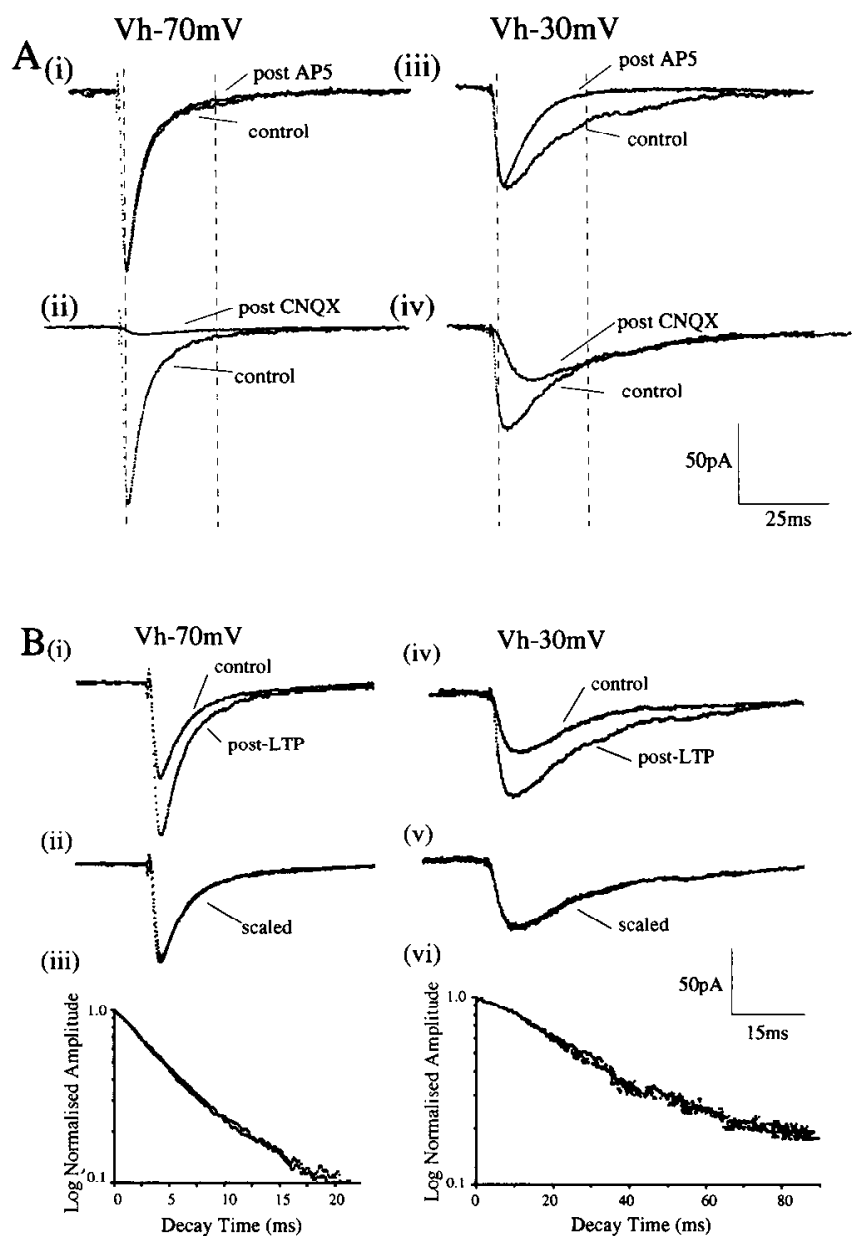

Figure 1. A, Time course of the excitatory postsynaptic currents (EPSCs). Left traces show the holding potential at $-70 \mathrm{mV}$, and right traces show the holding potential at $-30 \mathrm{mV}$. The dashed lines are drawn at $3 \mathrm{msec}$ and $25 \mathrm{msec}$ from the start of the EPSC. A(i,iii), Superimposed traces of the dual component AMPA/NMDA receptormediated EPSCs in control media and the isolated AMPA receptormediated component following application of AP5 $(50 \mu \mathrm{M})$ at a holding potential of $-70 \mathrm{mV}$ (i) and at $-30 \mathrm{mV}$ (iii). A(ii,iv), Superimposed traces of dual component AMPA/NMDA EPSCs in control media and the isolated NMDA component following application of CNQX $(5 \mu \mathrm{M})$ at a holding potential of $-70 \mathrm{mV}$ (iii) and at $-30 \mathrm{mV}$ (iv). Each trace is the average of three originals. $B$, LTP of the dual AMPA/NMDA EPSCs. $B(i, i i)$, Traces of the dual component EPSCs prior to, and following, the induction of LTP at -70 and $-30 \mathrm{mV}$, respectively. $B(i i i, v)$, The superimposed traces of the EPSCs prior to, and following, the induction of LTP, following the scaling down of the potentiated EPSCs, at -70 and $-30 \mathrm{mV}$, respectively. $B(i i i, v i)$, Graphs of the normalized amplitudes of the decay times of the EPSCs prior to, and following, the induction of LTP at -70 and $-30 \mathrm{mV}$, respectively.

dual decay time constants was carried out using SCAN, version 3.0. Values are the mean \pm SEM, and Student's $t$ test was used for statistical comparisons.

\section{Results}

Tetanically induced LTP of the AMPAR- and NMDARmediated component of the dual component EPSC

The time course of the AMPAR- and NMDAR-mediated components of the dual component AMPAR/NMDAR EPSC was assessed accurately by measuring the time course of the pharmacologically isolated AMPAR and NMDAR EPSCs, using 4 $6 \mu \mathrm{M}$ CNQX and $50 \mu \mathrm{M}$ AP5, respectively. Figure $1 A(i)$ shows 
that at $-70 \mathrm{mV}$, the EPSC had a $10-90 \%$ rise time of $1.1-2.2$ msec (mean $1.3 \pm 0.4 \mathrm{msec}$ ) and a main decay with a time constant $(\tau)$ of $9.5 \pm 2.3 \mathrm{msec}(n=12)$. The AMPAR component, isolated in the presence of AP5 [Fig. $1 A(i)]$, had a 10 $90 \%$ rise time of $1-2 \mathrm{msec}$ (mean $1.3 \mathrm{msec}$ ) and a single decay time with a $\tau$ of $7.9 \pm 2.8 \mathrm{msec}(n=8)$. The perfusion of CNQX resulted in a large decrease in the amplitude of the EPSC, leaving a relatively small amplitude isolated NMDAR EPSC [Fig. 1A(ii)]. Application of both AP5 (50 $\mu \mathrm{M})$ and CNQX (5 $\mu \mathrm{M})$ abolished the EPSC. Measurements of the contributions of the AMPAR and NMDAR receptor components to the dual component AMPAR/NMDAR EPSC were also made at $-30 \mathrm{mV}$, at which potential the $\mathrm{Mg}$ block of the NMDAR is removed and thus there is a much greater contribution of the NMDAR component to the dual component EPSC. At $30 \mathrm{mV}$, the dual component EPSC was considerably lengthened in duration due to this increased contribution of the NMDAR-mediated component [Fig. $1 A(i i i)$, with the 10-90\% rise time ranging from 6.8-11.5 msec (mean $9.7 \pm 1.1 \mathrm{msec}$ ) and a fast and slow decay time constant $\tau_{\mathrm{r}}$ and $\tau_{\mathrm{s}}$ of $36 \pm 18$ and $278 \pm 52 \mathrm{msec}$, respectively, $n=8$. At $-30 \mathrm{mV}$, the AMPAR EPSC, isolated in AP5, was reduced in amplitude but had a similar 10-90\% rise time (1.4$2.8 \mathrm{msec}$, mean $1.8 \pm 0.4 \mathrm{msec})$ and $\tau(6.1 \pm 1.9 \mathrm{msec}) \mathrm{com}-$ pared with those at a potential of $-70 \mathrm{mV}$ [Fig. 1A(iii)]. However, the pharmacologically isolated NMDAR EPSC had a much greater amplitude and also extended decay time at $-30 \mathrm{mV}$ than at $-70 \mathrm{mV}$ [Fig. $1 A(i \mathrm{v})]$, with a $10-90 \%$ rise time of $6-11 \mathrm{msec}$ (mean $8 \pm 1.9 \mathrm{msec}$ ), and dual decay time with a $\tau_{\mathrm{f}}$ of $45 \pm$ 19 and a $\tau_{s}$ of $320 \pm 48 \mathrm{msec}(n=8)$. These parameters of the AMPAR and NMDAR EPSCs are very similar to those recorded previously in dentate granule cells (Keller et al., 1991).

These measurements of the time course of the pharmacologically isolated AMPAR and NMDAR EPSCs demonstrated that the amplitude of the dual component EPSC at times $3 \mathrm{msec}$ and $25 \mathrm{msec}$ from the commencement of the EPSC were accurate measurements of the AMPAR- and NMDAR-mediated components, respectively, of the dual component EPSC. The amplitude of the AMPAR-mediated component of the EPSCs at $3 \mathrm{msec}$ at $-30 \mathrm{mV}$ and at $-70 \mathrm{mV}$ was $87 \pm 16$ and $151 \pm 22 \mathrm{pA}$, respectively $(n=8)$, while the amplitude of the NMDAR-mediated component of the EPSC at $25 \mathrm{msec}$ at $-30 \mathrm{mV}$ was 63 $\pm 15 \mathrm{pA}(n=5)$. The amplitude of the NMDAR EPSC at -70 $\mathrm{mV}$ was too small to be measured accurately.

The induction of LTP by tetanic stimulation induced a large increase in the amplitude of the EPSCs which was sustained for at least $25 \mathrm{~min}$. The amplitude of the AMPAR-mediated component of the EPSCs at $3 \mathrm{msec}$ at potentials of $-70 \mathrm{mV}$ and at $-30 \mathrm{mV}$ was $247 \pm 39 \mathrm{pA}$ and $132 \pm 23 \mathrm{pA}$, respectively [Fig. $1 B(i, i v) ; n=5$ ], while the amplitude of the NMDARmediated EPSC at $25 \mathrm{msec}$ at $-30 \mathrm{mV}$ was $103 \pm 18 \mathrm{pA}$ [Fig. $1 B(i v) ; n=5]$. Thus the increase of the AMPAR component of the EPSC following LIP induction was $152 \pm 9 \%$ and $164 \pm$ $10 \%$ of control at $-30 \mathrm{mV}$ and $-70 \mathrm{mV}$, respectively. The increase of the NMDAR-mediated component of the EPSC was $163 \pm 12 \%$ at $-30 \mathrm{mV}$. There was no significant difference between the amplitude of the LTP of the two components at $-30 \mathrm{mV}$.

Verification of this similar increase in amplitude of the AMPAR- and NMDAR-mediated components of the EPSC was provided by rescaling the amplitude of the post-LTP dual component EPSC down to the pre-LTP level. Figure $1 B$, (ii, iii) and $(v, v i)$, shows that following such rescaling at -30 and $-70 \mathrm{mV}$,
A

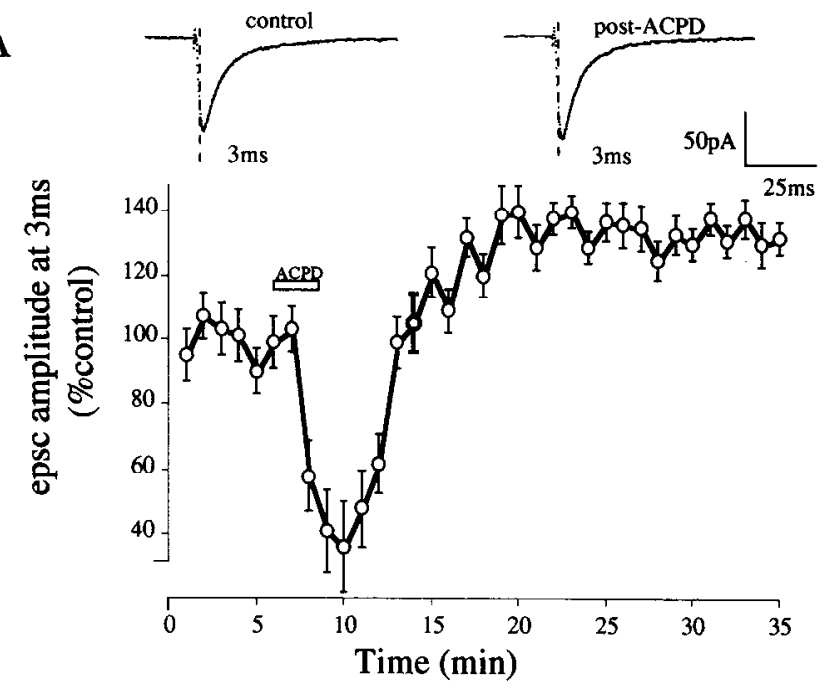

B
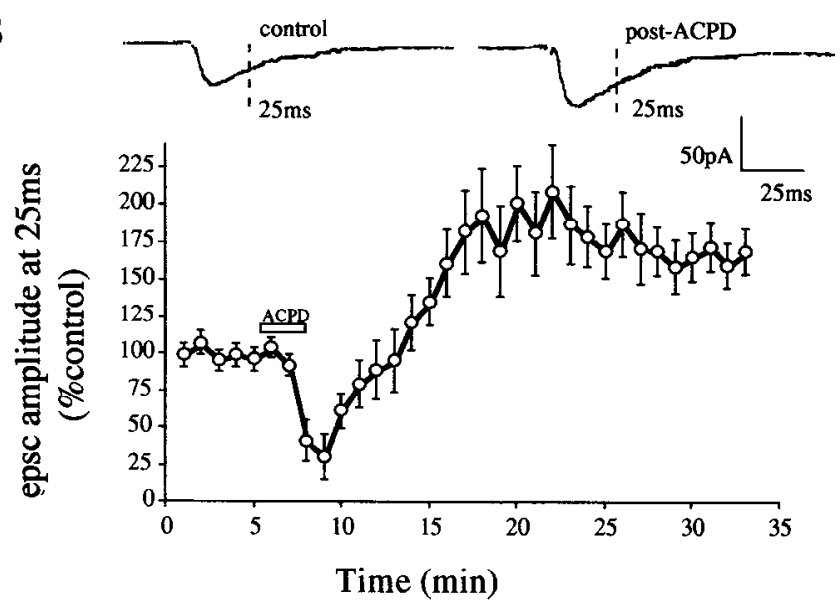

Figure 2. ACPD-induced LTP of the AMPA and NMDA receptormediated components of the dual EPSC. A, Amplitude of the AMPA receptor-mediated component of the EPSC at $-70 \mathrm{mV}$, measured at 3 msec, plotted against time. ACPD at $10 \mu \mathrm{M}$ applied for $2 \mathrm{~min}$ induced a transient depression followed by a rapid onset LTP which lasted without decrement for $30 \mathrm{~min}$. $B$, Amplitude of the NMDA receptor-mediated component at $-30 \mathrm{mV}$, measured at $25 \mathrm{msec}$, plotted against time. ACPD at $10 \mu \mathrm{M}$ applied for 2 min induced a transient depression followed by a rapid onset LTP which lasted without decrement for 30 min. Each graph shows the avcrage of six experiments. In each experiment, the holding potential was $-70 \mathrm{mV}$ and $300 \mathrm{msec}$ duration depolarizing steps to $-30 \mathrm{mV}$ were applied at $0.025 \mathrm{~Hz}$.

respectively, there was no change in the rise time or the decay time of the EPSCs.

\section{ACPD-induced LTP of the AMPAR-and NMDAR-mediated components of the dual component EPSC}

In these experiments, the holding potential was $-70 \mathrm{mV}$, and it was stepped to $-30 \mathrm{mV}$ for $300 \mathrm{msec}$ at a frequency of 0.025 Hz. ACPD at $10 \mu \mathrm{M}$ was perfused for $2 \mathrm{~min}$. The ACPD induced an initial transient depression lasting for 3-5 min of both the AMPAR-mediated component, measured at $3 \mathrm{msec}$ from the start of the EPSC, and the NMDAR-mediated component, measured at $25 \mathrm{msec}$, of the dual component AMPAR/NMDAR EPSC. This depression was followed by a rapidly rising potentiation of both components which reached a peak amplitude 8$10 \mathrm{~min}$ following ACPD application and persisted for at least 30 min without significant decrement (Fig. $2 A, B$ ). The mean LTP 

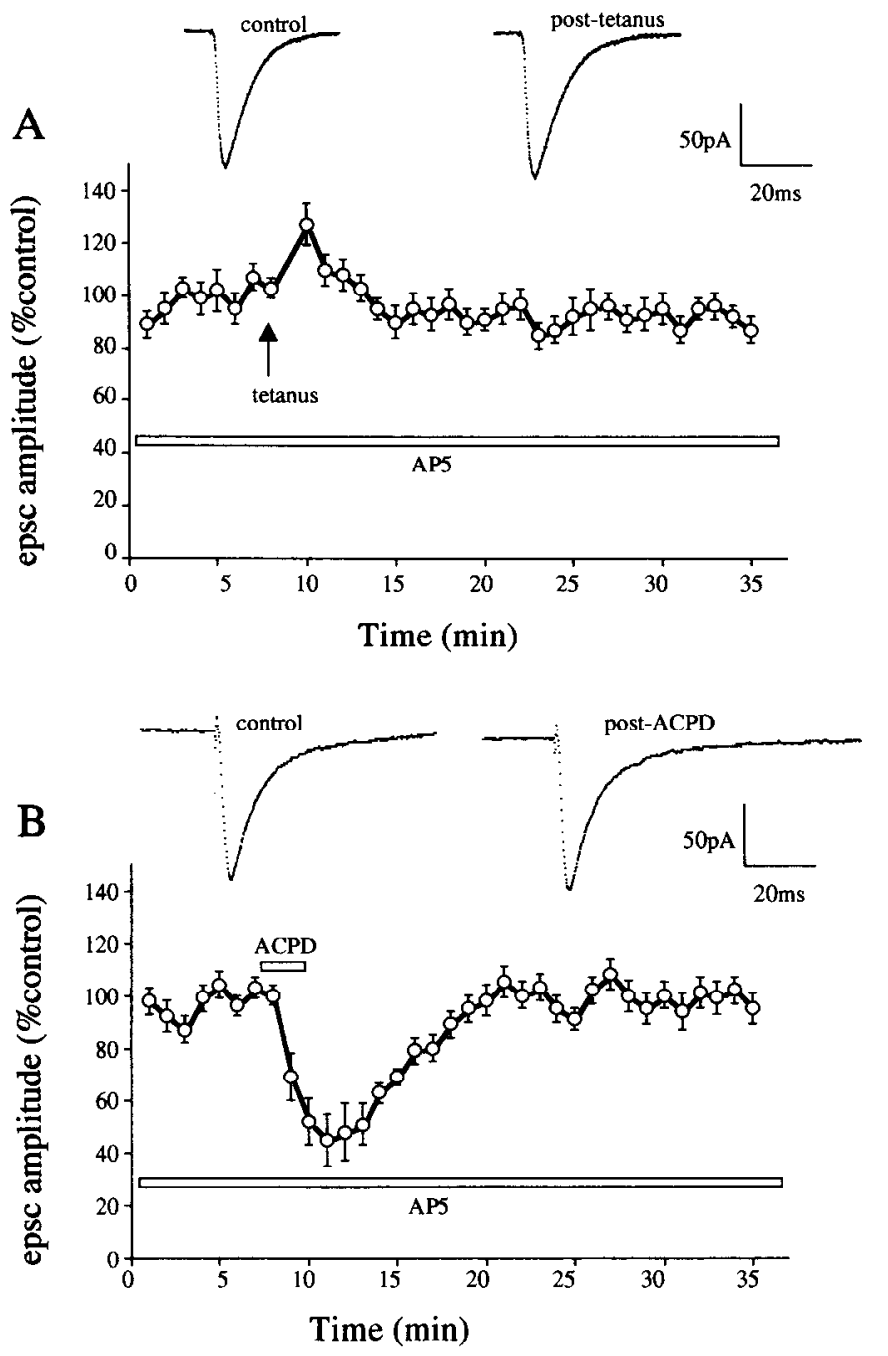

Figure 3. Absence of ACPD-induced and tetanically induced LTP of the isolated AMPA EPSC. $A$, Tetanic stimulation in the presence of AP5 $(50 \mu \mathrm{M})$ induced only a very small and brief short-term potentiation, and no LTP. Each graph shows the average of five experiments. $B$, Perfusion of $10 \mu \mathrm{M}$ ACPD for $2 \mathrm{~min}$ in the presence of AP5 induced only a transient depression of the AMPA EPSC, followed by a return to the control amplitude. The holding potential was $-70 \mathrm{mV}$.

of the AMPAR-mediated components at $20 \mathrm{~min}$ following ACPD application was $139 \pm 8 \%$ at $-70 \mathrm{mV}$, respectively, $n$ - 5, with all five cells showing potentiation (range 121-154\%). At a holding potential of $-30 \mathrm{mV}$, the mean AMPAR component potentiation was $132 \pm 8 \%$ and the mean NMDAR component potentiation was $203 \pm 8 \%, n=9$. The potentiation of the NMDAR-mediated component could be divided into two subgroups, with six cells showing a moderate potentiation (mean $148 \pm 9 \%$ ), and a further three cells showing a very large potentiation (mean $215 \pm 31 \%$ ).

Dependency of ACPD- and tetanically induced LTP of the AMPAR-mediated component of the EPSC on NMDAR activation

The NMDAR dependency of the tetanically and ACPD-induced LTP of the AMPAR-mediated component was investigated by applying tetanic stimulation (Fig. $3 A$ ) or ACPD (Fig. $3 B$ ) in the presence of the NMDAR antagonist AP5 $(50 \mu \mathrm{M})$. The holding potential in these experiments was also $-70 \mathrm{mV}$, and it was stepped to $-30 \mathrm{mV}$ for $300 \mathrm{msec}$ at a frequency of $0.025 \mathrm{~Hz}$. ACPD at $10 \mu \mathrm{M}$ was perfused for $2 \mathrm{~min}$. Under these conditions, tetanically induced LTP of the isolated AMPA EPSC (measured at $3 \mathrm{msec}$ from the start of the EPSC) was completely abolished (LTP 20 min post-tetanus was $97.6 \pm 6 \%, n=5$, range 89 $111 \%, P<0.001$; Fig. $3 A$ ), confirming previous studies (see Bliss and Collingridge, 1993). ACPD also failed to induce LTP of the isolated AMPAR EPSC in the presence of AP5, with the 20 min post-ACPD isolated AMPAR EPSC measuring $98.5 \pm$ $6 \%, n=5$, range $91-113 \%, P<0.01 \%$, although an initial transient depression did still occur (Fig. $3 B$ ).

\section{Tetanically and ACPD-induced LTP of pharmacologically isolated NMDAR EPSCs: dependency on NMDA receptor activation}

Tetanic stimulation induced an LTP of the NMDAR EPSCs which persisted for at least $30 \mathrm{~min}$ without significant decrement. The peak amplitude of the NMDAR EPSCs was routinely measured by stepping to a potential of $-30 \mathrm{mV}$ for $300 \mathrm{msec}$. LTP measured at $20 \mathrm{~min}$ post-tetanus averaged $172 \pm 15 \%$ of control. The rise time and dual decay time of the NMDAR EPSCs was not altered following LTP induced by tetanic stimulation, with the $10-90 \%$ rise time $8.2 \pm 1.9 \mathrm{msec}, \tau_{\mathrm{f}} 44 \pm 8$ msec, and $\tau_{\mathrm{s}} 297 \pm 53 \mathrm{msec}$ after potentiation.

Perfusion of $10 \mu \mathrm{M}$ ACPD induced an initial transient depression of the NMDAR EPSC followed by a potentiation which persisted for at least $30 \mathrm{~min}$ without significant decrement. The potentiation measured at $20 \mathrm{~min}$ post-ACPD application had a value $169 \pm 18 \%$ of control. No change in the rise time or decay time of the NMDAR EPSC was observed following the ACPD-induced potentiation (rise time $8.5 \pm 1.5 \mathrm{msec}, \tau_{\mathrm{f}}=39.5$ $\pm 5 \%, \tau_{\mathrm{s}}=357 \pm 61 \%$ ).

Experiments were carried out to determine whether it was necessary for transmitter activation of the NMDAR to occur during either tetanic stimulation or ACPD application in order for the induction of LTP to occur (Fig. $4 A-C$ ). It can be seen from Figure $4 A$ that following a control recording period of 5 min, AP5 $(50 \mu \mathrm{M})$ caused an abolition of the NMDAR EPSC within $4 \mathrm{~min}$, and that complete recovery occurred within 10 min. In one set of experiments, tetanic stimulation (under current-clamp conditions) was given in the presence of AP5, either paired with $(n=2)$ or without $(n=3)$ a depolarization to 0 IIIV (Fig. 4B). Following washout of the AP5, no significant LTP was observed, the amplitude of the NMDAR EPSC returning only to baseline values (peak amplitude $102 \pm 8 \%, n=5$ ). Confirmation that potentiation of the NMDAR EPSCs could occur in these cells was demonstrated by the ability of a tetanic train, applied following washout of the AP5, to evoke LTP. The LTP after such washout of AP5 measured $145 \pm 8 \%$ at $15 \mathrm{~min}$ post-tetanus ( $n=5$ ), a figure not statistically different from control in the absence of AP5. In another set of experiments, ACPD $(10 \mu \mathrm{M})$ was applicd for $2 \mathrm{~min}$ in the presence of AP5. Following washout of the AP5, no significant LTP of the NMDAR EPSC was observed, the amplitude of the NMDAR EPSC returning only to the baseline values (peak amplitude $98 \pm 7 \%$, $n=5$ ). Confirmation that ACPD-induced LTP could occur in these cells was demonstrated by the ability of ACPD application, following washout of the AP5, to evoke LTP measuring $132 \pm$ $8 \%$ at 15 min post-tetanus, values not significantly different from controls in the absence of AP5 (Fig. 4C). 


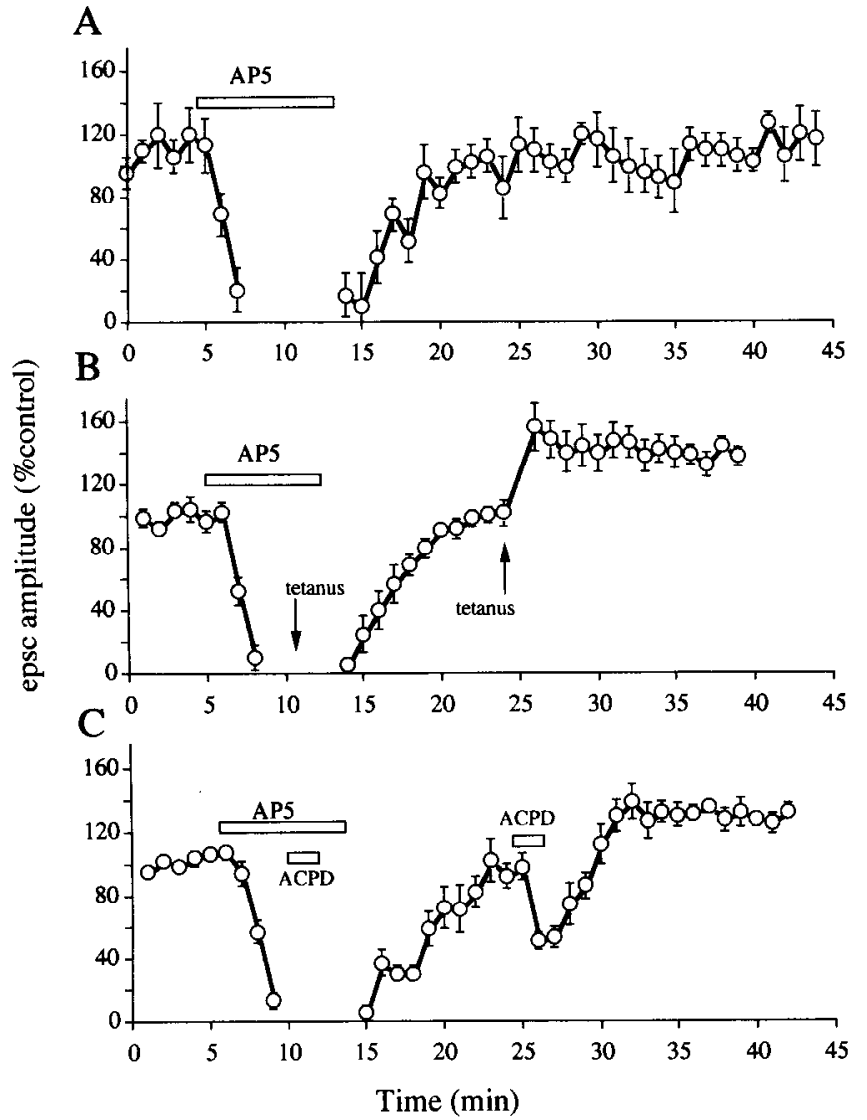

Figure 4. Inhibition of tetanically and ACPD-induced ITP of the NMDA EPSCs by AP5. AP5 $(50 \mu \mathrm{M})$ applied for 8 min led to a rapid loss of the NMDA EPSCs. A, Following washout of AP5 under control conditions, the NMD $\Lambda$ EPSCs recovered to control values in $10 \mathrm{~min}$. $B$, Tetanic stimulation (arrow) was applied during the inhibition of the NMDA EPSCs by AP5. Following washout of the AP5, the NMDA EPSC recovered only to the control level. A second telanus (arrow) was able to induce LTP. $C$, ACPD $(10 \mu \mathrm{M})$ was applied during the inhibition of the NMDA EPSC by AP5. Following washout of the AP5, the NMDA EPSC recovered only to the control level. A second application of ACPD was able to induce LTP. Each graph shows the average of six experiments.

\section{Dependency of LTP of NMDAR EPSCs on PKC stimulation}

The effect of the selective PKC pseudosubstrate peptide inhibitor PKCI was investigated on both the tetanically induced and the ACPD-induced potentiation by including PKCI $(30 \mu \mathrm{M})$ in the patch pipette solution. The presence of intracellular PKCI was found to abolish both the tetanically and the ACPD-induced LTP. Thus 20 min following tetanic stimulation or ACPD application, the amplitude of the EPSC was $96 \pm 8 \%$ (range $82-107 \%$ ) and $102 \pm 16 \%$ (range $84-115 \%$ ), respectively, $n=5$, in the presence of PKCI. These are significant reductions, $P<0.01$, compared with the amplitude of the tetanically induced and ACPDinduced LTP in separate new control experiments of $153 \pm 8 \%$ (range 142-165\%) and $149 \pm 9 \%$ (range 139-171\%), $n=5$, respectively (Fig. $5 A, B$ ). A short-term potentiation was present following tetanic stimulation or ACPD application. This shortterm potentiation was very small following tetanic stimulation, with a peak at $126 \pm 15 \%$ and a duration of about $5 \mathrm{~min}$, although it was larger following the ACPD application, with a peak at $142 \pm 9 \%$ and a duration of 10-15 min.
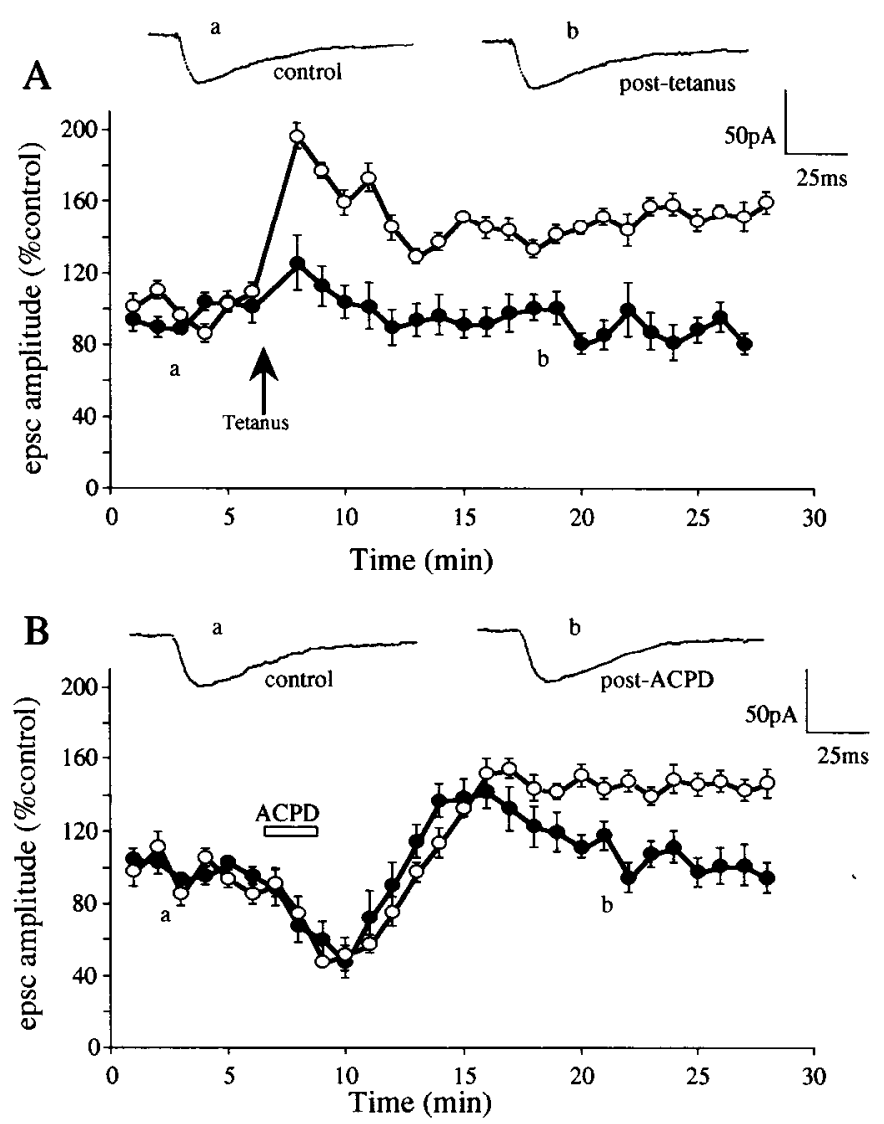

Figure 5. Inhibition of tetanically and ACPD-induced LTP of the NMDA EPSCs by the PKC inhibitor PKCI. A, Tetanic stimulation in control experiments $(O)$ in the absence of PKCI induced robust LTP. In the presence of PKCI $(30 \mu \mathrm{M})$ in the patch-clamp electrode (O), LTP was inhibited. $B$, Application of ACPD in control experiments induced LTP $(\bigcirc)$. In the presence of PKCI (O), LTP was inhibited, although a prominent STP lasting about $10 \mathrm{~min}$ was present. Each graph shows the average of six experiments.

\section{Discussion}

The main results of the present paper are that tetanic stimulation simultaneously induces an identical LTP of both the AMPARand NMDAR-mediated components of the EPSC, and that ACPD induces a relatively rapid onset, NMDAR-dependent LTP of both the AMPAR- and NMDAR-mediated components of the dual AMPA/NMDA receptor-mediated EPSC.

These present studies demonstrate that both the AMPAR- and NMDAR-mediated components of the dual component EPSC are simultaneously enhanced following the induction of LTP by tetanic stimulation, and the magnitude of the enhancement of each of these components of the EPSC was identical, resulting in the overall time course of the EPSC remaining identical following LTP induction. A recent abstract (Clarke and Collingridge, 1993) also describes a similar potentiation of AMPAR- and NMDAR-mediated EPSC components measured at $-60 \mathrm{mV}$. However, our results contrast with several previous studies which have either failed to show or have shown only a very small increase of the NMDAR component of the dual AMPAR/ NMDAR EPSP/EPSC following the induction of LTP by tetanic stimulation (Kauer et al., 1988; Muller and Lynch, 1988; Muller et al., 1988, 1992; Perkel and Nicol, 1993). A possible reason for the inability of several previous investigators to observe substantial LTP of the NMDAR EPSP/EPSC equivalent to that of 
LTP of the AMPAR EPSC is that over- or inappropriate activation of the NMDAR occurred during their experiments. It has previously been shown that strong activation of the NMDAR by removal of $\mathrm{Mg}$ or perfusion of NMDA receptor agonists prior to tetanic stimulation prevented the induction of LTP of the AMPA EPSP (Coan et al., 1989; Izumi et al., 1992). As we have shown that LTP of the NMDAR EPSC is also dependent upon NMDAR activation, we considered it a likely possibility that strong activation of the NMDAR prior to tetanic stimulation would also prevent or reduce LTP of the NMDAR component of the EPSC. Consequently, in the present experiments great care was taken to avoid overactivation of the NMDAR prior to tetanic stimulation. Thus the membrane potential was held at a relatively hyperpolarized level $(-70 \mathrm{mV})$ and test EPSCs were recorded only at a low frequency $(0.05 \mathrm{~Hz})$, with recordings at $-30 \mathrm{mV}$ for $300 \mathrm{msec}$ to assess the NMDAR component of the EPSC made only at a frequency of $0.025 \mathrm{~Hz}$.

The similar enhancement of both AMPAR and NMDAR components shown in this study would be expected if LTP induction was presynaptically mediated (see Bekkers and Stevens, 1990; Malinow and Tsien, 1990), or if postsynaptic mechanisms of LTP induction (see Foster and McNaughton, 1991; Manabe et al., 1992), such as changes in receptor functioning, were of a similar magnitude for both the AMPAR- and NMDAR-mediated components of the EPSC. An increase in the amplitude of a receptor-mediated synaptic current could theoretically be induced by an increase in the probability of opening of the receptor channel, an increase in single-channel conductance, or an increase in the duration of opening of the channel. The lack of change of the decay time course of both the AMPAR- and the NMDAR-mediated components of the F.PSC following the induction of LTP does not support the possibility that an increase in duration of opening of the AMPAR or NMDAR channel is responsible for the LTP, as such a change would be expected to increase the duration of the EPSC.

The ACPD-induced LTP of the AMPAR EPSC described in the present studies resembles much more closely tetanically induced LTP than the only previously demonstrated ACPD-induced LTP in the hippocampus (Bortolotto and Collingridge, 1993). First, the presently observed ACPD-induced LTP had a relatively rapid onset $(3-5 \mathrm{~min})$ and time to peak $(8-10 \mathrm{~min})$, and it is likely that this development time would be greatly slowed by the presence of the initial presynaptic transient depression following ACPD application; that is, an initial fast potentiation would be masked by the depression. In the previous study (Bortolotto and Collingridge, 1993), the ACPD-induced rise in the low-frequency-evoked field EPSPs was very slowly developing, with the peak amplitude obtained only after $90 \mathrm{~min}$. Second, the ACPD-induced LTP in the present study was dependent upon activation of NMDAR, with AP5 blocking such LTP. The previously recorded ACPD-induced potentiation of EPSPs was NMDAR independent (Bortolotto and Collingridge, 1993).

The present study therefore provides evidence that LTP of AMPAR-mediated synaptic transmission is induced by coactivation of both NMDAR and mGluR. Bashir et al. (1993) previously concluded that $\mathrm{mGluR}$ activation underlies a late-phase LTP in CAl, although not an early-phase LTP lasting $30 \mathrm{~min}$, on the basis of the finding that the duration of LTP was shortened by the mGluR antagonist $(R, S)$ - $\alpha$-methyl-4-carboxyphenylglycine (MCPG). However, it is possible that MCPG is not a sufficiently potent antagonist to block the early phase of LTP.
Further support for the present coactivation theory is the finding that a potentiation lasting $15 \mathrm{~min}$ was produced in $\mathrm{CA} 1$ when NMDA and ACPD were coapplied, although not when applied separately (Musgrave et al., 1993). A relatively fast onset LTP of intracellular EPSPs (peak attained in $30 \mathrm{~min}$ ) induced by ACPD has also previously been observed in the dorsolateral septal nucleus, although tetanically induced LTP is not dependent on NMDAR activation in that nucleus (Zheng and Gallagher, 1992).

These studies therefore provide evidence that activation of mGluR by the endogenous neurotransmitter during tetanic stimulation underlies the induction of LTP, including the early stage, of the AMPAR-mediated components of the EPSC. The previously reported enhancement of tetanically induced LTP in the presence of a low concentration of ACPD (McGuinness et al., 1991; Aniksztejn et al., 1992; Behnisch and Reymann, 1993) can be explained by this underlying role of the mGluR in LTP. It has become increasingly apparent that both a rise in intracellular Ca (Malenka et al., 1988) and stimulation of PKC is required for the induction of LTP of AMPAR-mediated synaptic transmission. Experiments using PKC inhibitors have found that PKC stimulation is required in the early phase (Wang and Feng, 1992; Hanse and Gustaffson, 1994) and the late phase (Malenka et al., 1989; Malinow et al., 1989) of LTP, and PKC subspecies have been demonstrated to be stimulated by $15 \mathrm{sec}$ following tetanic stimulation (Sacktor et al., 1993). Coactivation of the NMDAR and the mGluR during tetanic stimulation would provide both of these intracellular mediators, as there is extensive evidence that activation of mGluR stimulates PKC (Schoepp and Conn, 1993) and activation of NMDAR generates a rise in intracellular Ca (Mayer et al., 1987). A recent article by Bortolotto et al. (1994) has confirmed that coactivation of mGluR and NMDAR must occur in order to induce LTP of AMPAR, and, importantly, has also shown that temporally coincident activation of the two receptor types need not occur. Rather, activation of the mGluR leads to a conditioning state involving persistent activation of a protein kinase. Only the activation of NMDAR is temporally linked to induction of LTP (Bortolotto et al., 1994).

This investigation, together with our companion study (O'Connor et al., 1994), also provides strong evidence that LTP of NMDAR-mediated synaptic transmission is induced following activation of mGluR. Thus LTP of the NMDA EPSCs was previously shown to be blocked by the mGluR antagonists MCPG and L-2-amino-3-phosphonoproprionate (L-AP3), while the sclcctive mGluR agonist ACPD produced a long-lasting potentiation of the NMDAR EPSCs which was similar in amplitude, time course, lack of obvious voltage dependency, and block by mGluR antagonists to that following tetanic stimulation (O'Connor et al., 1994). In the present studies we have additionally shown that both the tetanically and ACPD-induced LTP were dependent on activation of the NMDAR, and inhibited by the $\mathrm{PKC}$ peptide inhibitor $\mathrm{PKCI}$.

Inhibition of NMDAR activation by the competitive antagonist AP5 during tetanic stimulation or during the application of ACPD was shown to block the induction of LTP of the NMDAR EPSC, findings which support those of Bashir et al. (1991), who showed that AP5 inhibited LTP of the field NMDAR EPSPs. These present results also appear to demonstrate that NMDAR and mGluR must be temporally coactivated coincidentally during the processes which induce LTP of NMDAR, as the activation of NMDAR following washout of the ACPD did not induce LTP. This conclusion concerning LTP of the NMDAR 
would differ from LTP of the AMPAR, since, as described above, it has been claimed that temporal coincident coactivation of mGluR and NMDAR is not required (Bortolotto et al., 1994). However, experiments similar to those carried out in the present studies, in which depolarization-induced activation of NMDAR at low frequency was given following $A C P D$ application and washout (and failing to induce LTP of NMDAR), were not carried out for LTP studies of the AMPAR by Bortolotto et al. (1994). The NMDAR activation is probably required for LTP of NMDAR in order to generate a rise in intracellular Ca. A rise in the intracellular $\mathrm{Ca}$ concentration had been found to be imperative for induction of LTP of NMDAR EPSPs, with intracellular injection of the Ca chelator BAPTA inhibiting the LTP (Xie et al., 1992). This rise in the intracellular $\mathrm{Ca}$ concentration may be necessary for adequate stimulation of PKC and the possibly subsequent phosphorylation of the NMDAR.

The results of the present study demonstrating that ITP of the NMDAR EPSCs induced by tetanic stimulation and ACPD were inhibited by the specific peptide $\mathrm{PKC}$ inhibitor suggest strongly that an endogenous PKC-mediated phosphorylation process is involved in such LTP, with a phosphorylation occurring directly of the NMDAR or of a site downstream of the NMDAR. A role for PKC has previously been suggested in the mediation of a reversible potentiation of $N M D \Lambda R$ responses in $C \Lambda 1$, as a spe cific $P K C$ peptide inhibitor and also sphingosine inhibited such reversible potentiation (Aniksztejn et al., 1992), although such reversible potentiation of NMDAR responses in CA1 has also been suggested to be independent of PKC (Harvey and Collingridge, 1992). Further evidence implicating a role of $\mathrm{PKC}$ in the potentiation of the NMDAR-mediated responses has been demonstrated by the ability of phorbol esters, agents which directly activate PKC, to enhance NMDAR-mediated responses in dorsal spinal horn neurons (Gerber et al., 1989) and oocytes (Kelso et al., 1992). Moreover, intracellular injection of PKC potentiated NMDAR-mediated currents in trigeminal neurons, an effect inhibited by a peptide PKC inhibitor (Chen and Huang, 1992).

\section{References}

Aniksztejn L, Otani S, Ben-Ari Y (1992) Quisqualate metabotropic receptors modulate NMDA currents and tacilitate induction of longterm potentiation through protein kinase C. Eur J Neurosci 4:500 505.

Asztely F, Wigstrom H, Gustaffson B (1992) The relative contribution of NMDA receptor channels in the expression of long-term potentiation in the hippocampal CAl region. Eur $J$ Neurosci 4:681-690.

Bashir ZI, Alford S, Davies SN, Randall AD, Collingridge GL (1991) Long-term potentiation of NMDA receptor-mediated synaptic transmission in the hippocampus. Nature 349:156-158.

Behnisch T, Reymann KG (1993) Co-activation of metabotropic glutamate and $N$-methyl-D-aspartate receptors is involved in mechanisms of long-term potentiation maintenance in rat hippocampal CA1 neurons. Neuroscience 54:37-47.

Bekkers JM, Stevens CF (1990) Presynaptic mechanism for long-term potentiation in the hippocampus. Nature 346:724-729.

Berretta N, Berton F, Brunelli M, Capogna M, Fransesconi W (1991) Long-term potentiation of NMDA receptor-mediated EPSP in Guinea-pig hippocampal slices. Eur $J$ Neurosci 3:850-854.

Bleakman D, Rusin KI, Chard PS, Glaum SR, Miller RJ (1992) Metabotropic glutamate receptors potentiate ionotropic glutamate responses in the rat dorsal horn. Mol Pharmacol 42:192-196.

Bliss TVP, Collingridge GL (1993) A synaptic model of memory: longtern polentiation in the hippocampus. Nature 361:31-37.

Bortolotto ZA, Collingridge GL (1993) Characterization of LTP induced by the activation of glutamate metabotropic receptors in area CAl of the hippocampus. Neuropharmacology 32:1-9.

Bortolotto ZA, Bashir ZI, Davies CH, Collingridge GL (1993) A mo- lecular switch activated by metabotropic glutamate receptors regulates induction of long-term potentiation. Nature 368:740-743.

Cerne R, Randic M (1992) Modulation of AMPA and NMDA responses in rat spinal dorsal horn neurons by trans-1-aminocyclopentane-1,3-dicarboxylic acid. Neurosci Lett 144:180-184.

Chen L, Huang LM (1991) Protein kinase $\mathrm{C}$ reduces $\mathrm{Mg}$ block of NMDA-receptor channels as a mechanism of modulation. Nature 356:521-523.

Clark KA, Collingridge GL (1993) Long-term potentiation of dual component EPSCs in the rat hippocampal slice. Soc Neurosci Abstr 19:905.

Coan EJ, Irving AJ, Collingridge GL (1989) Low frequency activation of the NMDA receptor system can prevent the induction of LTP. Neurosci Lett 105:205-210.

Collingridge GL. Kehl SJ. McLennan H (1983) The antagonism of amino acid-induced excitations of rat hippocampal CAl neurones in vitro. J Physiol (Lond) 334:19-31.

Collins CGS (1993) Actions of agonists of metabotropic glutamate receptors on synaptic transmission and transmitter release in the olfactory cortex. Br J Pharmacol 108:422-430.

Foster TC, McNaughton BL (1991) Long-term enhancement of CA1 synaptic transmission is due to increased quantal size, not quantal content. Hippocampus 1:79-.91.

Gerber G, Kanggrga I, Kyu PD, Larew JSA, Randic M (1989) Multiple effects of phorbol esters in the rat spinal dorsal horn. $J$ Neurosei 9:3606-3617.

Glaum SR, Miller RJ (1992) Metabotropic glutamate receptors mediate excitatory transmission in the nucleus of the solitary tract. $J$ Neurosci $12: 2251-2258$

Hanse E, Gustaffson B (1994) Staurosporine impairs both short-term and long-term potentiation in the dentate gyrus in vitro. Neuroscience 58:263-274.

Harvey J, Collingridge GL (1993) Signal transduction pathways involved in the acute potentiation of NMDA responses by $1 S, 3 R$-ACPD in rat hippocampal slices. Br J Pharmacol 109:1085-1090.

Harvey J, Frenguelli BG, Sunter DC, Watkins JC, Collingridge GL (1991) The actions of $1 S, 3 R$-ACPD, a glutamate metabotropic receptor agonist in area CAl of rat hippocampus. $\mathrm{Br} \mathrm{J}$ Pharmacol 104: $79 \mathrm{P}$.

Hestrin S, Nicoll RA, Perkel DJ, Sah P (1990) Analysis of excitatory synaptic action in pyramidal cells using whole-cell recordings from rat hippocampal slices. J Physiol (Lond) 422:203-225.

Izumi Y, Clifford DB, Zorumski CF (1992) Low concentrations of $\mathrm{N}$-methyl-D-aspartate inhibit the induction of long-term potentiation in rat hippocampal slices. Neurosci Lett 137:245-248.

Kauer JA, Malenka RC, Nicoll RA (1988) A persistent postsynaptic modification mediated long-term potentiation in the hippocampus. Neuron 1:911-917.

Keller BU, Konnerth A, Yaari Y (1991) Patch clamp analysis of excitatory synaptic currents in granule cells of rat hippocampus. J Physiol (Lond) 435:275-293.

Kelso SR, Nelson TE, Leonard JP (1992) Protein kinase C-mediated enhancement of NMDA currents by metabotropic glutamate receptors in Xenopus oocytes. J Physiol 449:705-718.

Malenka RC, Kauer JA, Zucker RS, Nicoll RA (1988) Postsynaptic calcium is sufficient for potentiation of hippocampal synaptic transmission. Scicnce 242:81-83.

Malenka RC, Kauer JA, Perkel DJ, Mauk MD, Kelly PT, Nicoll RA, Waxham MN (1989) An essential role for postsynaptic calmodulin and protein kinase activity in long-term potentiation. Nature 340 : 554-557.

Malinow R, Tsien R W (1990) Presynaptic enhancement shown by whole-cell recordings of long-term potentiation in hippocampal slices. Nature 346:177-180.

Malinow R, Schulman H, Tsien RW (1989) Inhibition of postsynaptic PKC or CaMKII blocks induction but not expression of LTP. Science 245:862-865.

Manabe T, Renner P, Nicol RA (1992) Postsynaptic contribution to long-term potentiation revealed by the analysis of miniature synaptic currents. Nature 355:50-55.

Mayer ML, MacDermott AB, Westbrook GL, Smith SJ, Barker JL (1987) Agonist and voltage gated calcium entry in cultured mouse spinal cord neurons under voltage clamp measured using arsenazo III. J Neurosci 7:3230-3244.

McGuinness N, Anwyl R, Rowan MJ (1991) Trans-ACPD enhances 
long-term potentiation in the hippocampus. Eur J Pharmacol 197: 231-232.

Muller D, Lynch G (1988) Long-term potentiation differentially affects two components of synaptic responses in hippocampus. Proc Natl Acad Sci 85:9346-9350.

Muller D, Jolly M, Lynch G (1988) Contribution of quisqualate and NMDA receptors to the induction and expression of LTP. Science 242:1694-1697.

Muller D, Arai A, Lynch G (1992) Factors governing the potentiation of NMDA receptor-mediated responses in hippocampus. Hippocampus 2:29-38.

Musgrave MA, Ballyk BA, Goh JW (1993) Coactivation of metabotropic and NMDA receptors is required for LTP induction. NeuroReport 4:171-174.

O'Connor JJ, Rowan MJ, Anwyl R (1994) Long-lasting enhancement of NMDA receptor-mediated synaptic transmission by metabotropic glutamate receptor activation. Nature 367:557-559.

Palmer E, Monaghan DT, Cotman CW (1989) Trans-ACPD, a selective agonist of the phosphoinositide-coupled excitatory amino acid receptors. Eur J Pharmacol 166:585-587.

Perkel DJ, Nicoll RA (1993) Evidence for all or none regulation of neurotransmitter release: implications for long-term potentiation. J Physiol (Lond) 471:481-500.

Sacktor TC, Osten P, Valsamis H, Jiang X, Naik MU, Sublette E (1993) Persistent activation of the $\zeta$ isoform of protein kinase $C$ in the maintenance of long-term potentiation. Proc Natl Acad Sci 90:8342-8346.

Schoepp DD, Conn PJ (1993) Metabotropic glutamate receptors in brain function and pathology. Trends Pharmacol 14:13-20.

Wang J, Feng D (1992) Postsynaptic protein kinase C essential to induction and maintenance of long-term potentiation in the hippocampal CA1 region. Proc Natl Acad Sci 89:2576-2580.

Xie X, Berger TW, Barrionuevo G (1992) Isolated NMDA receptormediated synaptic responses express both LTP and LTD. J Neurophysiol 67:1009-1013.

Zheng F, Gallagher JP (1992) Metabotropic glutamate receptors are required for the induction of long-term potentiation. Neuron 9:163172 